\title{
ALCOHOL AND MARIJUANA USE AMONG COLLEGE STUDENTS: ECONOMIC COMPLEMENTS OR SUBSTITUTES?
}

\author{
Jenny Williams \\ Rosalie Liccardo Pacula \\ Frank J. Chaloupka \\ Henry Wechsler \\ Working Paper 8401 \\ http://www.nber.org/papers/w8401 \\ NATIONAL BUREAU OF ECONOMIC RESEARCH \\ 1050 Massachusetts Avenue \\ Cambridge, MA 02138 \\ July 2001
}

We gratefully acknowledge research support for this paper from the Robert Wood Johnson Foundation through the IMPACTEEN and Substance Abuse Policy Research Program (SAPRP). Dr. Pacula's time was also partially supported by a grant from the National Institute on Drug Abuse (grant number R01DA12724-0). The views expressed herein are those of the authors and not necessarily those of the National Bureau of Economic Research.

(C) 2001 by Jenny Williams, Rosalie Liccardo Pacula, Frank J. Chaloupka and Henry Wechsler. All rights reserved. Short sections of text, not to exceed two paragraphs, may be quoted without explicit permission provided that full credit, including (C) notice, is given to the source. 
Alcohol and Marijuana Use Among College Students:

Economic Complements or Substitutes?

Jenny Williams, Rosalie Liccardo Pacula, Frank J. Chaloupka and Henry Wechsler

NBER Working Paper No. 8401

July 2001

JEL No. I10

\begin{abstract}
$\underline{\text { ABSTRACT }}$
College campuses have been cracking down on underage and binge drinking in light of recent highly publicized student deaths. Although there is evidence showing that stricter college alcohol policies have been effective at discouraging both drinking in general and frequent binge drinking on college campuses, recent evidence from the Harvard School Of Public Health College Alcohol Study (CAS) shows that marijuana use among college students rose 22 percent between 1993 and 1999. Are current policies aimed at reducing alcohol consumption inadvertently encouraging marijuana use? This paper begins to address this question by investigating the relationship between the demands for alcohol and marijuana for college students using data from the 1993, 1997 and 1999 CAS. We find that alcohol and marijuana are economic complements and that policies that increase the full price of alcohol decrease participation in marijuana use.
\end{abstract}

Jenny Williams, Ph.D.

University of Illinois at Chicago and University of Adelaide

Rosalie Liccardo Pacula, Ph.D.

The RAND Corporation and National Bureau of Economic Research

Frank J. Chaloupka, Ph.D.

University of Illinois at Chicago and National Bureau of Economic Research

Henry Wechsler, Ph.D.

Harvard School of Public Health 


\section{Introduction}

Prevalence statistics from population surveys consistently show that substance use and abuse among college students is higher than estimates from the general population. For example, the 1999 Monitoring the Future Survey (MTF) reports annual prevalence rates for alcohol, marijuana and any illicit drug use among 19 to 28 year olds college students to be $83.6 \%, 35.2 \%$ and $36.9 \%$, respectively. By comparison, prevalence rates for all young adults aged 19 to 28 were reported to be $84.1 \%$ for alcohol use, and $27.6 \%$, and $30.3 \%$ respectively for marijuana and any illicit drug use (USDHHS, 2000). The higher use rates among college samples are particularly disturbing because they are frequently accompanied by serious health consequences, acts of violence and/or crime, poor performance in school, and other negative outcomes (Presley, et al, 1996; Wechsler et al., 1994).

In an effort to reduce substance use and abuse among college students, Congress passed the Drug-Free Schools and Communities Act of 1986, which set aside funds for substance abuse prevention programs in higher education. However, the first survey on drinking and illicit drug use on college campuses, the Harvard School of Public Health College Alcohol Study (CAS), revealed that in 1993 two in five $(44.0 \%)$ of college students were binge drinkers (Wechsler et al., 1994) and that one in four (24.8\%) students had used marijuana in the past year (Bell, et al., 1997). ${ }^{1}$ As media attention on alcohol-related tragedies occurring on college campuses heightened, a new wave of private and public initiatives aimed at curbing underage and binge drinking began ${ }^{2}$. In addition, numerous states and localities began passing tighter alcohol control policies specifically targeting alcohol use and abuse among minors.

\footnotetext{
${ }^{1}$ Binge drinking in the Harvard School of Public Health College Alcohol Study is defined as a specific pattern of drinking involving the consumption of five or more drinks in a row on a single drinking occasion in the past two weeks for men and four or more drinks in a row on a single drinking occasion in the past two weeks for women. ${ }^{2}$ Examples of such programs include the counter-advertising campaigns of the National Association of State Universities and Land Grant Colleges, the Robert Wood Johnson Foundation's Matter of Degree program, and the U.S. Department of Education Fund for Improvement of Secondary Education Programs (Wechsler et al., 2000a).
} 
Recent research shows that some of these state and local policies have been effective at reducing alcohol use and binge drinking among college students. In particular, higher beer taxes, tougher drunk driving laws, state restrictions on happy hour pricing and restrictions on social access have all been associated with reduced drinking and/or binge drinking among college students (Chaloupka and Wechsler, 1996; Czart, 2001). In addition, some campus policies, such as total bans on drinking on campus, have been associated with an increased level of abstinence from alcohol use and lower levels of heavy episodic drinking among college students (Wechsler et al, 2001). At the same time, however, marijuana use among college students has been on the rise. Trend data from the 1993 and 1999 CAS shows an increase in thirty-day prevalence rates of marijuana use of $21.7 \%$ (a 2.8 percentage point increase) from 1993 to 1999 (Gledhill-Hoyt et al, 2000). Data from the Monitoring the Future Survey (MTF) show a similar rise in marijuana prevalence rates of $26.0 \%$ (a 7.3 percentage point increase) from 1993 to $1999 .^{3}$

The rise in marijuana use rates during a period in which tougher alcohol policies have been enacted raises the question as to whether recent alcohol policies have had the unintended consequence of raising illicit drug use among the college population. If alcohol and marijuana are economic substitutes for college students then these policies may not have the overall effect desired. However, it may be the case that the recent rise in college marijuana use merely reflects a broader societal trend that is independent of the policies being enacted. ${ }^{4}$

This paper begins to explore this question by examining the relationship between the demands for alcohol and marijuana among college students to determine if alcohol and marijuana are economic substitutes or complements. Previous studies examining the issue of complementarity and substitutability between alcohol and marijuana are inconclusive and do not

\footnotetext{
${ }^{3}$ Prevalence rates for other illicit drugs (excluding marijuana) also rose. According to data from the CAS, thirty day prevalence of other illicit drug use rose 20.8\% from 1993 to 1998 from 4.48\% to 5.41\% (Gledhill-Hoyt et al. 2000). Data from the MTF college sample shows an even larger increase in self-reported other illicit drug use (USDHHS, 2000).
} 
explicitly address the relationship between these two substances in this key population. We begin by examining own- and cross-price effects in annual and thirty-day prevalence equations for alcohol and marijuana for all students. Additional policy variables capturing the nonmonetary components of price, such as accessibility and the legal environment for using each substance, are also examined. We find evidence that alcohol and marijuana are economic complements. Specifically, we find that increasing the monetary costs of marijuana use decreases participation in both marijuana and alcohol use. Also, policies that reduce access to alcohol, such as banning alcohol consumption on campus or state laws restricting happy hours, reduce both alcohol and marijuana use.

We then examine whether differences exist in the relationship between these two substances by gender and age. We find a differential response to campus alcohol bans between males and females, with bans having a significant impact on female alcohol and marijuana use only. We find no difference in the impact of policy variables on marijuana use across individuals less than 21 compared to those of legal dinking age. The proximity of the college location to major drug routes is found to have a differential impact on participation in alcohol use between age groups. In particular, we find that the distance from the school to a major drug trafficking route is negatively related to drinking among students who are of legal drinking age but has no affect on the probability of drinking among students who are minors.

\footnotetext{
${ }^{4}$ Data from the National Household Survey on Drug Abuse show that marijuana use among youth ages 12-17 more than doubled between 1990 and 1997, from 4.4 to $9.7 \%$ (SAMHSA, 1998). The aging of this youth population to college age may be what is driving the rise in annual use rates among college students.
} 
The rest of this paper is laid out as follows. In the following section we review the literature on the relationship between alcohol and marijuana use. In section three, we present the statistical model on which our empirical work is based. Section 4 describes the data used in this study, and section 5 contains our results. We conclude with a discussion of our findings in section 6 .

\section{Literature Review}

During the past decade a growing economic literature has emerged investigating the contemporaneous relationship between the demands for alcohol and marijuana in the general and youth populations. ${ }^{5}$ Initial studies evaluating the relationship between demands in youth and young adult populations concluded that alcohol and marijuana were economic substitutes (Chaloupka and Laixuthai, 1997; DiNardo and Lemeiux, 1992). Subsequent articles that have attempted to include additional proxies for the price of marijuana or that have examined more recent cohorts have generally found evidence of complementarity between alcohol and marijuana use, although the finding is often limited to specific populations (Farrelly et al 1999; Saffer and Chaloupka, 1999; Pacula, 1998; Thies and Register, 1993). The main exception has been a recent study conducted on household data from Australia (Cameron and Williams, 2001).

DiNardo and Lemieux (1992) were the first to examine the relationship between demands for alcohol and marijuana. Using state-aggregated data on high school seniors from 1980 through 1989 from the Monitoring the Future Surveys, they estimated prevalence equations for alcohol and marijuana that included the price of alcohol, the minimum legal drinking age and marijuana decriminalization. They found that marijuana decriminalization had a significant and negative effect on the prevalence of alcohol use by high school seniors although it had no

\footnotetext{
${ }^{5}$ A much more extensive literature on the epidemiology of substance use and the developmental pattern of drug use has existed in the sociology literature since the mid-1970s. These studies tend to focus on how and whether early use of alcohol and cigarettes leads to subsequent use of marijuana and other illicit drugs, a process which has become known as the "gateway effect." For more on this see Kandel, 1975 Kandel \& Yamaguchi, 1993 ; Golub and Johnston, 2001.
} 
significant effect on marijuana use. In addition, they found that higher minimum legal drinking ages were associated with higher marijuana use. They concluded from these two findings that alcohol and marijuana are economic substitutes for youth.

Using micro-level data on drinking behavior among high school seniors from the 1982 and 1989 Monitoring the Future Surveys, Chaloupka and Laixuthai (1997) confirmed DiNardo and Lemieux's (1992) earlier finding. They estimated both the frequency of drinking as well as the probability of heavy drinking and found that both were inversely related to beer prices and state decriminalization status, again suggesting that alcohol and marijuana are economic substitutes among youth. Separate analyses of the 1989 data that included measures of the wholesale or retail price of commercial grade or sinsemilla marijuana in nineteen cities found that for the majority of specifications there was a positive relationship between drinking frequency and heavy use and marijuana price. This finding, however, was sensitive to the measure of marijuana price employed. Specifications that used the retail price of sinsemilla marijuana actually show a negative and statistically significant relationship between marijuana price and drinking behavior.

Thies and Register (1993) were the first to use individual level data to estimate demand equations for both alcohol and marijuana use. Using data from the 1984 and 1988 National Longitudinal Survey of Youth, they estimated probit and Tobit specifications for alcohol, marijuana and cocaine that included measures of marijuana decriminalization status and minimum legal purchasing ages. No measure of the monetary price of alcohol was included in their models. They found that state decriminalization status had a positive effect on alcohol and cocaine use but no significant effect on marijuana use making them uncomfortable interpreting its significance in the other drug equations. Similarly they found that higher minimum legal purchasing ages had no significant effect on use of alcohol in 1984 although it appeared to be 
positively related to marijuana use (although not significantly so). They concluded that there is insufficient evidence of a substitution effect.

Pacula (1998) extended the analysis conducted by Thies and Register (1993) by estimating the conditional and unconditional demands for alcohol and marijuana using the 1984 National Longitudinal Survey of Youth using specifications that included measures of the full price of both substances. She found that increases in the beer tax or the legal drinking age decrease the demand for marijuana by at least as much in percentage terms as they decrease alcohol consumption, providing the first evidence of a complementary relationship between alcohol and marijuana. Although state decriminalization status was associated with lower levels of alcohol use, she also found that it was negatively associated with marijuana use, raising some doubt regarding how to interpret this variable in both equations.

Saffer and Chaloupka (1999) conducted the most comprehensive analysis of cross-price effects to date. Using data from the 1988, 1990 and 1991 waves of the NHSDA they estimated annual prevalence equations for marijuana, cocaine and heroin participation in addition to a continuous measure of the number of days alcohol was used in the past month for specific ethnic, gender and age subgroups. County-level alcohol prices and state-level marijuana decriminalization laws were used as measures of price for alcohol and marijuana, respectively. State-level prices for cocaine and heroin were also included in all of their specifications including crossprice effects so as to control for any relationship alcohol and marijuana demands have with cocaine and heroin. They find strong evidence of complementarity between alcohol and marijuana for the full sample, white (non-Hispanic) males and African-Americans. However, for two subgroups, Native Americans and Hispanics, the data show that alcohol and marijuana are economic substitutes. They find no significant cross-price effects for Asians, women or youth. The variation in the relationship between demands across different ethnic, gender and age groups 
is important in light of the fact that it is often ignored when general policies are being considered.

In an effort to continue exploring the differential relationship between demands across different subgroups, Farrelly et al (1999) used data from the 1990-1996 NHSDA to estimate probit specifications of marijuana use in the past 30 days for youth (ages 12-20) and young adults (21-30) separately. Average state-level beer prices were constructed from the American Chamber of Commerce Research Association's city-specific quarterly price data and merged with the data to capture movements in the price of alcohol. To capture the full price of marijuana, several different state-level measures were examined, including the fraction of marijuana possession arrests to total arrests, the annual number of cultivated marijuana plants eradicated in each state, the median fine for possession of any positive amount of marijuana. State-fixed effects were also included to control for unobserved factors that might be correlated with price and/or consumption. Beer price was only found to have a negative and significant effect on marijuana participation for youths (ages 12-20), suggesting a complementary relationship between alcohol and marijuana for this age group. No significant cross-price effect existed for the young adult sample.

Cameron and Williams (2001) provided the first international estimates of the cross-price effects between alcohol and marijuana. Using Australian data from the 1988, 1991, 1993, and 1995 National Drug Strategy Household Survey, Cameron and Williams took advantage of statelevel variation in cannabis prices and criminal status of marijuana to estimate past year participation equations for alcohol, marijuana and cigarettes. Their findings of a positive and significant effect of the price of alcohol in the marijuana equation suggest that marijuana and alcohol are economic substitutes for Australians. Separate analyses were not done by subgroups, however, to determine if this finding is consistent across different ethnic, gender and age groups in the population. 
The recent evidence showing differential relationships between alcohol and marijuana use by age groups suggests that a separate analysis of college students could be particularly useful in light of the policies being targeted at this specific population. In addition, as noted by Gledhill-Hoyt et al (2000), there are a number of factors that put college students at greater risk than other young adults at developing illicit drug use behaviors, including absence of parental controls and oversight, the tendency of college students to try new, previously prohibited behaviors, and the economic ability to afford illicit drugs. These factors suggest that a careful analysis of the relationship between the demands for these two drugs among college students is needed. This paper begins to fill this void by examining the relationship between the demands for alcohol and marijuana, focusing our analysis on own- and cross-price effects, for the full population and for important demographic groups (males, females, minors and those of legal drinking status). We include additional measures of price and availability of marijuana that are frequently ignored in the previous literature. In addition we control for unobserved school and state specific effects so that we can correctly attribute associations to the policies themselves.

\section{THE MODEL}

The decision to use alcohol and/or marijuana among college students can be described by the latent variable model:

(1) $\mathrm{A}_{\mathrm{ij}}{ }^{*}=\mathrm{X}_{\mathrm{ij}} \beta+\mathrm{P}_{\mathrm{j}} \phi+\varepsilon_{\mathrm{ij}}$

(2) $\mathrm{M}_{\mathrm{ij}}{ }^{*}=\mathrm{X}_{\mathrm{ij}} \alpha+\mathrm{P}_{\mathrm{j}} \kappa+\mu_{\mathrm{ij}}$

where $\mathrm{A}_{\mathrm{ij}}{ }^{*}$ and $\mathrm{M}_{\mathrm{ij}}{ }^{*}$ are underlying continuous measures of the true demand for, or net utility from consuming, alcohol and marijuana respectively, of the $i$ th individual residing in community

$j$. These latent measures of demand are derived from the standard utility-maximizing framework. $\mathrm{X}_{\mathrm{ij}}$ represents individual $(i)$ and community-level $(j)$ factors that are related to the marginal benefit and marginal cost of using alcohol and/or marijuana, such as the individual's gender, age, religious upbringing, and characteristics of the college that the student attends. $\mathrm{P}_{\mathrm{j}}$ 
represents a vector of prices an individual living in community $j$ faces for alcohol and marijuana and is intended to represent both the monetary and non-monetary components of price, such as the expected legal sanctions associated with using these substances, and social access.

We do not observe the net benefit of consuming alcohol or marijuana, only whether or not the student decides to use each of these substances. The probability that a student decides to use alcohol and marijuana respectively, therefore, can be written as follows:

(3) $\operatorname{Prob}\left(\mathrm{A}_{\mathrm{ij}}=1\right)=\operatorname{Prob}\left(\mathrm{X}_{\mathrm{ij}} \beta+\mathrm{P}_{\mathrm{j}} \phi+\varepsilon_{\mathrm{ij}}>0\right)$

(4) $\operatorname{Prob}\left(\mathrm{M}_{\mathrm{ij}}=1\right)=\operatorname{Prob}\left(\mathrm{X}_{\mathrm{ij}} \alpha+\mathrm{P}_{\mathrm{j}} \kappa+\mu_{\mathrm{ij}}>0\right)$

Here, $\mathrm{A}_{\mathrm{ij}}$ and $\mathrm{M}_{\mathrm{ij}}$ are dichotomous indicators that are set equal to one when the person is observed to be using alcohol or marijuana respectively. Assuming that $\varepsilon_{\mathrm{ij}}$ and $\mu_{\mathrm{ij}}$ have standard normal univariate distributions, we can estimate the above probit models using maximum likelihood estimation. ${ }^{6}$

Before these models can be estimated, there remains an outstanding statistical issue arising from our use of multilevel data that must be addressed. In addition to using individual level data from the college students, we employ information on the monetary and non-monetary components of price of marijuana and alcohol that are measured at both the college level $\left(\mathrm{P}_{c}\right)$ and the state level $\left(\mathrm{P}_{s}\right)$. For example, in the case of alcohol, we have measures of social access at both the college level (alcohol consumption banned on campus, availability of on-campus housing prohibiting use of alcohol, number of bars within a mile of campus) and the state level (restrictions on happy hours and low price sales, and open container laws). At each of these levels, there may be additional unobserved variables impacting social access that remain

\footnotetext{
${ }^{6}$ Bivariate probit models that account for unobserved correlation in the error terms across alcohol and marijuana participation equations were also estimated. Although significant positive correlation was found in the error terms, these bivariate models did not produce meaningful differences in coefficient estimates or their statistical significance for our main policy variables so the findings are omitted from the paper. The lack of a meaningful difference in findings despite significant correlation in the error terms is perhaps due to the fact that we used the same set of regressors in both models.
} 
unaccounted for. These common unobservables induce a correlation among the error terms of individuals coming from the same school and/or state "cluster".

The state level unobserved component of the error terms is particularly problematic as unobserved state factors are likely to be highly correlated with our included state level policy variables. For example, a key component of the full cost of marijuana use is the expected cost of legal penalties associated with using the drug, which we capture through a variable representing the maximum fine associated with possession of an ounce of marijuana for each state. However, the expected cost of legal sanctions is determined by both the penalties imposed in the event of being apprehended and the probability of being apprehended. If states with harsher penalties are less likely to enforce the laws, then the expected penalty may be lower in states with higher penalties. As we have no measure of enforcement, unobserved enforcement is accounted for in the error term. This is problematic if the unobserved state sentiment regarding enforcement is correlated with our measure of legal penalties, because our estimates will suffer omitted variable bias. Similarly, state attitudes about drinking or heavy drinking are likely to be correlated with the state beer tax, our measure of the monetary price of alcohol. Depending on the nature of this correlation, estimates of own- and cross-price effects may be biased upward or downward. To ameliorate the potential bias caused by these omitted variables, we include state identifiers in our specification of the empirical model.

The correlation in error terms among individuals attending the same college is due in large part to the sampling methodology employed in the survey, discussed below. Given that we have no a priori assumptions regarding the correct specification of the variance-covariance matrix within college clusters and how it could relate to omitted measures of price, we use the general robust cluster adjustment of standard errors within school clusters to correct for this unobserved correlation. The empirical model estimated, therefore, is given by: 
(5) $\operatorname{Prob}\left(\mathrm{A}_{\mathrm{i}}=1\right)=\Phi\left(\mathrm{X}_{\mathrm{ij}} \beta+\mathrm{P}_{\mathrm{c}} \phi_{1}+\mathrm{P}_{\mathrm{s}} \phi_{2}+\mathrm{S}_{\mathrm{s}} \pi\right)$

(6) $\operatorname{Prob}\left(\mathrm{M}_{\mathrm{i}}=1\right)=\Phi\left(\mathrm{X}_{\mathrm{ij}} \alpha+\mathrm{P}_{\mathrm{c}} \kappa_{1}+\mathrm{P}_{\mathrm{s}} \kappa_{2}+\mathrm{S}_{\mathrm{s}} \lambda\right)$

where $S_{s}$ is a vector of state indicators, $P_{c}$ and $P_{s}$ represent components of the full price of alcohol and marijuana use measured at the college and state level respectively. Standard errors are adjusted for clustering at the college level using the cluster option in STATA version 7.0 .

\section{DATA}

\section{IV.1 THE HARVARD SCHOOL OF PUBLIC HEALTH COLLEGE ALCOHOL STUDY}

We pool information on students' alcohol and marijuana use from the 1993, 1997 and 1999 waves of the CAS a nationally representative study of full-time students at four year colleges. In 1993, a random sample of 173 schools were selected from the American Council on Education's list of accredited universities using probability weights proportional to the size of each college. The sample was then augmented to improve representation of women's colleges and small colleges. Out of a final sample of 195 colleges, $140(72 \%)$ chose to participate in the 1993 survey. Administrators at each college were asked to provide a random sample of undergraduates drawn from the total enrollment of full-time students, and strict guidelines were provided regarding how to generate this sample. Over 200 students from each school were sent an anonymous survey in February of 1993. The surveys were mailed to the students at their registered school addresses. Over 17,000 students $(17,582)$ responded to the survey. ${ }^{7}$ In addition to interviewing students, school administrators were interviewed to obtain detailed information pertaining to campus policies.

In 1997 and 1999, the original 140 colleges were resurveyed. One hundred thirty colleges participated in the 1997 survey, and 128 participated in the 1999 survey. The main reason given by colleges for not participating in the subsequent surveys was that they were

\footnotetext{
${ }^{7}$ Response rates varied significantly across schools. For more details regarding the sampling design and response rates in the 1993, 1997 and 1999 surveys, see Wechsler et al. (1994), Wechsler et al. (1998), and Wechsler et al. (2000b).
} 
unable to provide a random sample of students and their addresses within the time frame designated by the study. In 1997 and 1999, student samples were obtained using the same procedures as the 1993 survey, resulting in a sample of 15,685 students in 1997 and 14,907 students in 1999. School administrators were also re-interviewed to obtain information on changing alcohol and tobacco campus policies.

Although the CAS was designed to examine binge drinking behavior across US college campuses, other risky behaviors were also examined including smoking, illicit drug use, and sexual activity. Of particular interest to this study is the student's self-reported use of alcohol and marijuana in the past month, and the past year. In each survey, students were asked the following, "When did you last have a drink (that is more than just a few sips)?" A dichotomous indicator was created indicating past year use if an individual responded that they had either had alcohol "More than 30 days ago, but less than a year ago", "More than a week ago, but less than 30 days ago", or "Within the last week." An indicator for use in the past month was constructed on the basis the whether the respondent reported having last had a drink "More than a week ago, but less than 30 days ago", or "Within the last week."

Information on the student's past use of marijuana comes from the following question, “How often, if ever, have you used... marijuana (or hashish)?” Separate dichotomous indicators set equal to one were constructed for those students who reported using marijuana within the past 12 months, and within the past 30 days.

In addition to information on smoking marijuana and drinking, the student survey obtained detailed socioeconomic and demographic information. Thus it is possible to construct controls for important correlates of young adult substance use identified in the literature. Variables constructed for this analysis include: the age of the respondent (in years), age squared; an indicator for gender (male), race (White, Black, Asian, Native American), ethnicity (Hispanic, non-Hispanic), the religion that they grew up in (Catholic, Jewish, Moslem, Protestant, other 
religion, and no religion), parents' education (at least one parent completed college), and indicators of each parent's drinking behavior while the respondent was growing up (parent not present, abstainer, former drinker, moderate drinker, heavy drinker, problem drinker). The college level characteristics controlled for are: an indicator for the college being a women's college, a historically black college, a commuter college, a small private college, a large private college, a large public campus, a small public campus.

\section{IV.2 PRICE AND POLICY VARIABLES}

Information on the full price of marijuana and alcohol has been merged into the CAS data from a variety of sources. Information on the monetary price of marijuana come from various publications of the Illegal Drug Price/Purity Report, (IDPPR) published by the DEA Office of Intelligence or Intelligence Division of the U.S. Department of Justice. Although other sources of marijuana price data are available, the IDPPR published data represents the only source we are aware of in which it is possible to distinguish high and low quality marijuana consistently over time for the same locations. The IDPPR report the minimum and maximum retail (ounce) and wholesale (pound) price of commercial-grade and sinsemilla marijuana in 19 cities located in 16 states. $^{8}$ These 19 cities represent main branch offices for the DEA. The price and quality information are obtained for purchases made by undercover police officers and DEA agents that are sent to a laboratory at the University of Mississippi for analysis. For the purposes of this analysis, we focus on the quarterly prices for commercial marijuana sold at the retail level. ${ }^{9}$

\footnotetext{
${ }^{8}$ The cities for which quarterly prices are published are Atlanta, Georgia; Boston, Massachusetts; Chicago, Illinois; Dallas, Texas; Denver, Colorado; Detroit, Michigan; Houston, Texas; Los Angeles, California; Miami, Florida; Newark, New Jersey; New Orleans, Louisiana; New York, New York; Philadelphia, Pennsylvania; Phoenix, Arizona; San Diego, California; San Francisco, California; Seattle, Washington; St. Louis, Missouri; and the District of Columbia.

${ }^{9}$ The retail price is clearly the price that would be most relevant to young adults' consumption decisions. The choice to focus on commercial-grade marijuana rather than sinsemilla grade has to do with fact that there were fewer missing observations for these data. In addition, there is some evidence that commercial grade marijuana dominated the US marijuana market during this period (National Narcotics Intelligence Consumers Committee, 1998).
} 
There are two principal limitations of the IDPPR 19 cities data. First, quarterly data are not complete for all cities in each year and are particularly sparse in the later part of the 1990's. In order to produce a complete and consistent price series for our analysis, we make use of the full set of information we have on the minimum retail price for commercial marijuana, which includes quarterly observations from 1982-1998, by forming the predicted price based on the following regression model:

$$
\ln \left(\frac{\mathrm{p}_{\mathrm{jt}}}{\mathrm{CPI}_{\mathrm{t}}}\right)=\sum_{\mathrm{j}} \beta_{1 \mathrm{j}} \operatorname{city}_{\mathrm{j}}+\beta_{2 \mathrm{j}} \text { city }_{\mathrm{j}} * \text { year }_{\mathrm{t}}+\varepsilon_{\mathrm{jt}}
$$

Here $\mathrm{p}_{\mathrm{jt}}$ is the minimum retail price of commercial marijuana in city $\mathrm{j}$ in time period $\mathrm{t}$, city $(j=1, \ldots 19)$ is a set of city dummies for the DEA 19 cities, and year is a time trend. Since our measure of marijuana use is use in the past year, we match the predicted price in year t-1 to our survey data in year $\mathrm{t}$.

A second limitation of these data is that they exist only for 19 locations in 16 states. However, further investigation of the data revealed that several DEA branch offices report to each of these 19 cities offices. We used this additional information to assist us with matching college campuses to city-specific prices by matching each college to the closest within-state branch office that reported data to a 19 cities office. Each college campus was assigned the predicted minimum price for commercial-grade marijuana based on the 19 cities office that their matched DEA branch office reported to. Although specific campuses are matched to different branch offices, these branch offices report only to the 19 cities offices, so several schools are inevitably given the same predicted price. This price may be a better or worse approximation for the actual price faced by students at a particular school depending on the fraction of purchase observations that came from the campus' matched DEA branch office as well as the local variation in price in that area. 
Because we are concerned about the measurement error that is introduced by matching 140 schools in 40 states to price data available only in 19 specific cities, we include an additional proxy to help us capture the variation in expected price that might exist due to measurement error. This is based on the distance between the school location and the matched DEA branch office location. The price of marijuana on a college campus is likely to depend upon, among other things, the proximity of that location to major drug trafficking routes. Those schools closer to major drug routes are likely to experience lower prices than schools that are farther away. Assuming that the DEA branch offices are concentrated on major drug traffic routes, we use the distance between the school location and the matched DEA branch office location as a measure of this component of the money price of marijuana. For those schools in which no within-state DEA branch office existed, we matched them to the closest out-of-state branch office and created an additional indicator specifying that an out-of-state match was made to correct for any measurement error introduced by these poor quality matches.

In addition to the money cost, the full price of marijuana use includes the expected social and legal penalties faced. We attempt to account for state-level variation in these non-monetary components of price by including the state-level maximum fine for possession of one ounce of marijuana and an indicator for whether marijuana use has been decriminalized in the respondent's state of residence. ${ }^{10}$ Data on the legal penalties associated with possession of an ounce of marijuana were compiled from various secondary sources, including the Sourcebook of Criminal Justice Statistics and the National Organization for Reform of Marijuana Laws (NORML), for the years 1990-1997. Penalty information for 1999 come from original legal research conducted by The MayaTech Corporation as part of the ImpacTeen: State Illicit Drug Project. Information on state decriminalization status come from NORML. States that have

\footnotetext{
${ }^{10}$ We also experimented with the median of the maximum and minimum fines. Our results are not sensitive to this distinction.
} 
decriminalized marijuana typically reduce the criminal penalties associated with possession of specified amounts of marijuana to simple fines with no associated jail terms.

Information on the monetary cost of alcohol is proxied by the CPI deflated sum of federal and state taxes (measured in cents) on a twelve ounce can of beer. ${ }^{11}$ These data are published annually in the Beer Institute's Brewers' Almanac. Although beer is not the only alcohol beverage consumed by college students, it is frequently reported as the drink of choice (Czart, 2001) and thus is perhaps the most relevant for this analysis.

We measure non-monetary aspects of the full price of alcohol by state and campus level variables related to access and opportunity to use. In terms of state level policies governing access, we include indicators for state level restrictions on happy hours, state level restrictions on low price sales, and state level open container laws. We capture campus level access to alcohol using an indicator for the school banning alcohol use on campus for all students and whether the campus offers substance free dorms. To capture off-campus access to alcohol, we include a set of indicators representing whether there were 0,1 or more than 1 bar within a mile radius of the school campus. $^{12}$

Several studies have found interdependencies in the demands for alcohol, marijuana and cigarettes. In order to control for this in our examination of the relationship between alcohol and marijuana, we also include the price of cigarettes in our models. ${ }^{13}$ We merge data on the state average price of cigarettes, obtained from various publications of the Tobacco Institute's Tax Burden on Tobacco, based on the state location of the school campus. The cigarette price is a

\footnotetext{
${ }^{11}$ Other studies have used ACCRA alcohol price index as a measure of the cost of alcohol. We do not use this measure because of the additional measurement noise that it introduces because of imperfect matches between ACCRA cities and college campus locations. Czart (2001) presents findings of various alcohol demand models using the CAS data and alternative measures of price from ACCRA and the beer tax that suggests that the ACCRA findings are unreliable.

${ }^{12} \mathrm{~A}$ continuous measure for the number of bars within a one mile radius was not available for all three years. We also explored models that included an indicator for those colleges in dry counties. This measure of availability was highly correlated with the number of bars within a mile, so only the bar variable is included in the models presented here.

${ }^{13}$ Demand equations for cigarettes are not included in this paper because school cigarette policy variables, which have been shown to be important correlates of cigarette use, are only available for the 1997 and 1999 surveys.
} 
state average cigarette price, based on the price of single cigarette packs, cartons and vending machine sales. It reflects the average price of a branded pack of twenty cigarettes inclusive of state level excise taxes.

Descriptive statistics for the pooled sample of the 1993, 1997 and 1999 waves of the CAS, along with price and policy variables are reported in Table 1. The sample size reflects the number of observations for which we have non-missing data. It should be noted that the total number of observations used in this study differs from the research conducted by Wechsler et al. (2000) who use the subset of 119 schools for which the response rate is at least $50 \%$ in two of the three surveys and a rate of at least $40 \%$ in the third.

Tables 2.1 and 2.2 contain simple cross tabulations of marijuana and alcohol use in the past month and year. Amongst college students surveyed, approximately two thirds (four fifths) had used alcohol in the past month (year), and about 15\% (27\%) had used marijuana during the same time period. It is also noteworthy that while the majority of students who use alcohol do not use marijuana, practically all marijuana users also consumed alcohol during the same time period.

As discussed in the previous section, omitted state level characteristics may potentially bias our estimates of the effect of our price and policy variables if the omitted factors are correlated with these variables. In order to address this issue, we include a set of state indicators in our models of marijuana and alcohol use. However, because there has been almost no change in several of our key state-level policies variables, including state decriminalization status, the beer tax, and legislation governing happy hours, low price alcohol sales, and open containers, during the time period under analysis there is insufficient information to identify the effects of these policy variables in addition to the set of state indicators. Rather than omit these policy variables from our analysis completely, our strategy is to estimate models without state effects that include these policy variables in addition to models with state effects. While allowing us to 
ascertain the role of these important policy variables in the decision to participate in alcohol and marijuana use, this approach also facilitates an investigation into the nature of potential biases introduced by omitting state indicators.

\section{RESULTS}

In this section, we present the results from estimating 30 day and annual participation equations for marijuana and alcohol use. The focus of our analysis is in establishing the economic relationship between alcohol and marijuana for college students. Because of this we only present findings on measures of the full price of alcohol and marijuana in the text. Tables A.1 and A.2 in the Appendix contain the full set of results for thirty-day prevalence of alcohol and marijuana use, respectively. ${ }^{14}$

Tables 3 and 4 contain the estimated marginal effects and standard errors for probit models of participation in marijuana and alcohol use in the past 30 days and the past year respectively. The top panel of both of these tables present findings from specifications that include state identifiers. The lower panels present findings from specifications that exclude state identifiers, but include other relevant state-level policy variables such as marijuana decriminalization status, the beer tax, and state restrictions on happy hours, pitcher sales and open containers. Standard errors in all of these models are adjusted for the clustering of observations at the school level. ${ }^{15}$

As the main results are robust to our measure of past use, we focus our discussion on the findings from the past month prevalence equations presented in Table 3. Looking first at our models with state indicators included, we find that both measures of the money price of marijuana (the DEA 19 cities matched price and the number of miles between the respondent's

\footnotetext{
${ }^{14}$ Full results for the annual participation models are available from the authors upon request.
} 
school and the closest DEA reporting office) are negative and significant in the marijuana participation equation although the 19 cities matched price is only significant at the $10 \%$ level (two-sided test). This provides evidence that, as with other illicit and licit drugs, marijuana use is price responsive. The own price elasticity for participation in monthly (annual) marijuana use is estimated to be $-0.27(-0.21)$. In addition, the DEA 19 cities matched price is negative and significant in the alcohol use equation, suggesting a complementary relationship between alcohol and marijuana. With state identifiers included, the out of state matching dummy variable is insignificant in both the marijuana and alcohol participation equations.

The non-monetary costs of using an illicit drug such as marijuana include the expected legal and social sanctions. We attempt to account for these costs with the maximum fine for marijuana possession. Ceteris paribus, we expect that greater legal sanctions increase the cost of using marijuana, and hence reduce the probability of use. However, this variable is estimated to have a positive, albeit very small, impact on the prevalence of marijuana use that is statistically significant at the $10 \%$ level in the thirty-day prevalence equation (it is not statistically significant in the annual prevalence equation). When we compare the findings for this variable in models with and without state identifiers, it is clear by the fact that the coefficient on maximum fine declines both in magnitude and significance that the state identifiers are picking up some of the omitted variable bias caused by unmeasured enforcement patterns. However, the fact that the maximum fine for marijuana use remains statistically positive suggests that there remains differences across states in terms of enforcement that are unaccounted for by the state identifiers.

Turning to the impact of the campus level alcohol policy variables in the model with state effects, we find that banning the consumption of alcohol on campus reduces participation in alcohol use and participation in marijuana use. This finding is only statistically significant at the

\footnotetext{
${ }^{15}$ Because of the matching of marijuana price data to 19 cities, we also ran models examining price effects adjusting for clustering at the 19 cities level. The standard errors from these regressions were less conservative than those presented in the paper.
} 
$10 \%$ level in the thirty-day prevalence equations, however. Nonetheless, it provides some further support of a complementary relationship between these two drugs. Interestingly, our second measure of access to alcohol at the campus level, the set of indicators for the number of outlets selling alcohol within a mile of campus, has a positive and significant impact on the probability of alcohol use in the past thirty days, but has no statistically significant impact in the marijuana use equations. This positive and significant finding on alcohol use disappears in the annual prevalence equation. Neither the provision of alcohol free dorms, nor the price of cigarettes is found to have any significant impact on either the decision to use alcohol or marijuana in the past thirty days.

State indicator variables are included in the models of substance use in an attempt to account for omitted or unobserved state level characteristics associated with use that are potentially correlated with included policy variables. However, addressing this issue comes at the cost of investigating the impact of the effect of state level alcohol policy variables, such as the legal status of marijuana use, the state and federal taxes on beer, and state level restriction on happy hours, low prices, and open container laws, which exhibit very little variation over time. The high degree of multicollinearity between these particular policy variables and state indicators means that the effects of the variables can not be separately identified from the state indicators. In order to investigate the role of these important policy variables, we now turn to the models estimated without state effects. We begin by discussing the results for decriminalization of marijuana and the alcohol policy variables omitted from the previous analysis. We then compare results across the specifications with and without state effects to investigate the extent of any bias introduced by omitting state indicators from the models.

Marijuana decriminalization is found to have a positive but statistically insignificant effect on alcohol and marijuana use in all models estimated. This finding is perhaps not that surprising in light of the fact that many states that have not formally decriminalized marijuana 
still have reduced penalties for first time offenders possessing small amounts of marijuana, including diversion options that expunge the offense from their criminal record. In addition, legal research conducted by the MayaTech Corporation as part of the ImpacTeen initiative reveals that four out of the eleven so-called decriminalized states still identify possession offenses as misdemeanor offenses and hence they are still technically crimes. ${ }^{16}$ This combined with the fact that reduced penalties exist in non-decriminalized states suggests that future research should more carefully examine the nuances of penalty structures across states so as to correctly identify those states that truly have reduced penalties for possession of marijuana.

We find that the beer tax, our proxy for the money price of alcohol, has a negative impact on the prevalence of both alcohol and marijuana use. This effect is only statistically significant in the alcohol equation however. We interpret this finding as evidence that alcohol consumption is price responsive. We further interpret the negative finding in the marijuana prevalence equation as supporting our general finding of a complementary relationship between these two substances. This result is statistically significant on the basis of a 1 sided test at the $10 \%$ level of significance in the case of annual marijuana use. Similarly, state level policy variables that impact access to alcohol also tend to support the economic relationship between alcohol and marijuana as complementary. In particular, we find that happy hour restrictions have a significantly negative impact on both marijuana and alcohol use. Open container laws, which significantly reduce the prevalence of drinking also have a negative effect on marijuana use, although this finding is not significant at conventional levels.

Although the exclusion of state level indicators generally increases the significance of policy variables previously found to be important, there is one very notable exception: the 19 cities matched price of marijuana. When state identifiers are omitted from the model, the estimated coefficient on the 19 Cities DEA marijuana price variable is substantially reduced

\footnotetext{
${ }^{16}$ This information was obtained through personal correspondence with Jamie Chriqui of the MayaTech Corporation
} 
while the standard error falls moderately. Thus, the variable is no longer significant in these models. Given that our DEA price data cover 19 cities in 16 states, it is perhaps not surprising to find evidence that unmeasured state characteristics are correlated with this variable. This is further supported by the fact that the out-of-state match dummy variable becomes positive and statistically significant in the models omitting state level indicators. This suggests to us that the state identifiers were also capturing important unobserved state-level variation in price. We do not interpret it as evidence that marijuana is unresponsive to changes in its own price because we still find a negative and statistically significant finding for our second measure of the monetary price of marijuana: the miles between college and DEA reporting office. Recall that this additional measure of the money price of marijuana proxies the higher transportation costs faced by students at colleges further away from major drug routes.

\section{Differences across gender and age}

Previous findings of a differential response of substance use to policy variables by gender and age-group (see Saffer and Chaloupka (1999), and Farrelly et al. (1999), for example) suggest that an investigation of the robustness of our findings across these subpopulations is warranted. The usual approach to examining whether sub-samples can be pooled is the standard likelihood ratio test, which compares the unrestricted model (which allows for differential responses across subgroups) to the restricted model (imposing no differences across groups). However, when data are clustered, as ours are, this test is not appropriate. This is because the observations are no longer independent, and so the joint distribution function for the sample is not the product of the distribution functions for each observation. ${ }^{17}$ Since the likelihood used to estimate coefficients does not reflect the correlation among observations, testing should be carried out using the Wald test. This test is based on the unrestricted model, that allows for differential responses by group. 
In testing for gender (age) differences, we estimate the unrestricted models for marijuana and alcohol use in the past thirty days by including a full set of interaction terms between regressors and an indicator for gender is male (student of legal drinking age). ${ }^{18}$ The Wald test for whether there is any significant difference in response between males and females (minors and students 21 years or older) is then a test of joint significance of these interaction terms. The p-values associated with the test of the joint significance of the interaction terms is 0.0160 $(0.0008)$ for marijuana use and $<0.0001(<0.0001)$ for alcohol use in the last thirty days. We conclude that there are significant differences across gender (age) in the response to at least one of the regressors. Table 5 presents point estimates of marginal effects and standard errors for the price and policy variables on marijuana and alcohol use in the past thirty days for each of our sub-groups. The first two columns present findings for males and females while the last two columns present findings for minors and students of legal drinking age.

One of the benefits of using the Wald testing procedure is that, in addition to testing the joint significance of all interaction terms, it facilitates examining whether subsets of coefficients differ significantly across sub-groups. Of particular interest to this study is whether responses to policy variables are significantly different. Beginning with the results for males and females, the p-values for the test of joint significance of the interaction terms on the policy variables in the marijuana and alcohol use equations are 0.045 and 0.04 , respectively, indicating that there is a differential response to at least one of these variables across gender. Further inspection of the significance of the interaction terms (not shown in the table) revealed that the only policy variable that has a statistically significant differential affect on males and females in either the

\footnotetext{
${ }^{17}$ Moreover, writing down the likelihood for the sample requires the correlation within clusters to be fully parameterized, as in the random effects model. As discussed in the model section, we do not explicitly specify the nature of the correlation within clusters. Rather, we use the robust estimator of the variance-covariance matrix.

${ }^{18}$ Similar models were estimated looking at annual prevalence with and without state fixed effects and thirty-day prevalence without state fixed effects. The findings with respect to gender and age differences were robust across these specifications. We do not allow for differences in unobserved state or year effects in carrying out these tests.
} 
alcohol or the marijuana participation equation is the bans on drinking on campus. ${ }^{19}$ As can be seen in Table 5, bans have a significantly negative impact on the use of alcohol and marijuana for females, but they have no significant impact on use of either of these substances among males.

Although many of the other policy variables are significant for both males and females, such as the price of marijuana in both the alcohol and marijuana equations, there is no statistical difference in their marginal effect across gender. The findings with respect to the monetary price of marijuana suggest that alcohol and marijuana are economic complements for both males and females. There conclusion of complementary for females is further supported by the negative and statistically significant affect of bans on both alcohol and marijuana consumption.

We follow the same strategy to determine whether there are age differences between college students in terms of their response to policy variables. The p-value for testing the null hypothesis that the interaction terms on the policy variables are jointly insignificant in the marijuana use equation is 0.826 . We therefore conclude that there is insufficient evidence to indicate a difference in the response to any of the policy variables on marijuana use across these two age groups. The $\mathrm{p}$-value for testing the joint significance of the interaction terms in the alcohol use equation is 0.091 , providing weak evidence of a differential effect in at least one policy variables. Further testing revealed that only the miles between school and DEA reporting office is statistically different across age groups. ${ }^{20}$ Findings in Table 5 show that this variable has a negative and statistically significant effect on the likelihood of drinking for students of legal drinking age and no significant effect on drinking by minors.

Because there were so few differences in the marginal effect of policy variables on use by age group, most of our findings with respect to the significance of particular policy variables

\footnotetext{
${ }^{19}$ A test that the effect of all policy variables other than the alcohol ban variable do not differ significantly between gender is accepted for both substances (with p-values of 0.116 in the case of marijuana use and 0.574 for alcohol use respectively).
} 
remain for both age groups. Again, we find that the monetary price of marijuana, as indicated by both our 19 cities match price and the miles from school to the DEA site, has a negative and statistically significant effect in both the alcohol and marijuana prevalence equations suggesting a complementary relationship between alcohol and marijuana use. Due to the multicollinearity induced by including the full set of interaction terms, none of the alcohol variables provide additional support for this conclusion, however.

\section{DISCUSSION}

The overwhelming evidence in this study, generated from examination of own- and cross-price effects, suggests that alcohol and marijuana are economic complements for college students. The finding of complementarity does not appear to be driven by any one particular demographic group dominating the sample, although insufficient sample size precludes us from doing a careful analysis by race/ethnicity. In addition to finding a negative relationship between the monetary price of marijuana and the probability of using both marijuana and alcohol, results with respect to college level measures of social access to alcohol also support a complementary relationship. In particular, campus bans on alcohol use are associated with a lower probability of using alcohol and marijuana in the general model, for females, and across different age groups, but not for males. Evidence from models including the beer tax and state level policies governing access to alcohol provide further support for a complementary relationship between alcohol and marijuana use.

It is clear from this study that recent efforts to reduce college students' social access to alcohol, and curb their binge drinking, has not contributed to the rise in marijuana use among this group. In particular, we find that campus bans on alcohol use are associated with a lower prevalence of marijuana use. Our results suggest that the more likely explanation for the rise in marijuana use among college students is the fact that college students' use of marijuana is price

\footnotetext{
${ }^{20}$ A test that all interactions with policy variables other than the miles variable are statistically insignificant cannot
} 
responsive. Given that the price of marijuana has dropped significantly during the past decade (ONDCP, 2000), it is not surprising that the prevalence of use in this price responsive group has risen.

One final observation warrants mentioning. In all of the models evaluated, we included a measure of the price of cigarettes to help control for interdependencies in the demands for alcohol, marijuana and cigarettes. The only model for which the price of cigarettes has a significant effect on either alcohol or marijuana use is the specification of annual marijuana use excluding state identifiers. This suggests that for college students there is no significant relationship between cigarettes and alcohol use and/or cigarettes and marijuana use, but further investigation may be warranted given that we do not control for other aspects of tobacco control policy. 


\section{References}

Bell R, Wechsler H and Johston LD. 1997. "Correlates of college student marijuana use: results of a US National survey." Addiction 92(5): 571-581.

Cameron L and Williams J. 2001. Substitutes or Complements? Alcohol, Cannabis and Tobacco. Economic Record 77 no. 236: 19-34.

Chaloupka, FJ and Laixuthai A. 1997. Do youths substitute alcohol and marijuana? Some econometric evidence. Eastern Economic Journal 23: 253-276.

Chaloupka FJ and Wechsler H. 1996. Binge Drinking in College: The Impact of Price, Availability, and Alcohol Control Policies. Contemporary Economic Policy 14: 112-124.

Czart C. 2001. "The Impact of Alcohol Control Policies on Alcohol Use and Abuse Among College Students" University of Illinois Chicago Dissertation.

DiNardo J and Lemiuex T. 1992. Alcohol, marijuana and American youth: The unintended effects of government regulation (Working Paper No. 4212). Cambridge, MA: National Bureau of Economic Research.

Farrelly MC; Bray JW; Zarkin GA; Wendling BW and Pacula RL. 1999. The effects of prices and policies on the demand for marijuana: Evidence from the National Household Surveys on Drug Abuse (Working Paper No. 6940). Cambridge, MA: National Bureau of Economic Research.

Gledhill-Hoyt J; Lee, H; Strote, J and Wechsler H. 2000. Increased use of marijuana and other illicit drugs at US colleges in the 1990s: results of three national surveys. Addiction 95(11): 1655-1667.

Golub A. and Johnston B. 2001. Variation in youthful risks of progression from alcohol and tobacco to marijuana and to hard drugs across generations. American Journal of Public Health 91(2): 225-233.

Johnston, L.D., O'Malley, P.M., \& Bachman, J.G. 2000. National survey results on drug use from the Monitoring the Future study, 1975-1999 Volume II: College students and young adults (NIH Publication No. 00-4803). Rockville, MD: National Institute on Drug Abuse.

Kandel, D. 1975. Stages I adolescent involvement in drug use. Science. 190: 912-914.

Kandel D and Yamaguchi K. 1993. From beer to crack: Developmental patterns of drug involvement. American Journal of Public Health 83: 851-855.

National Narcotics Intelligence Consumer Committee (NNICC). 1998. The NNICC report, 1997: The supply of illicit drugs to the United States. Washington, D.C.: Drug Enforcement Administration.

Office of National Drug Control Policy. 2000. What America's Users Spend on Illegal Drugs: 1988-1998. [U.S. Government Printing Office: Washington DC]. 
Pacula RL. 1998. Does increasing the beer tax reduce marijuana use? Journal of Health Economics 17: 557-586.

Presley, CA., Meilman, PW, and Cashin JR. (1996). Monograph IV: 1992-1994. Core Insitute, Southern Illinois University at Carbondale (October).

Saffer H and Chaloupka FJ. 1999. Demographic Differentials in the Demand for Alcohol and Drugs. In The Economic Analysis of Substance Use and Abuse (Chaloupka, Grossman, Bickel and Saffer Eds). University of Chicago Press, Chicago.

Substance Abuse and Mental Health Services Administration (SAMHSA), 1998. Preliminary results from the 1997 National Household Survey on Drug Abuse: Fact Sheet. US Department of Health and Human Services, Rockville, MD.

Substance Abuse and Mental Health Services Administration (SAMHSA), 2000. Summary of Findings from the 1999 National Household Survey on Drug Abuse. US Department of Health and Human Services, Office of Applied Studies. Rockville, MD.

Thies CF and Register CA. 1993. Deriminalization of marijuana and the demand for alcohol, marijuana and cocaine. Social Science Journal 30: 385-399.

US. Department of Health and Human Services (USDHHS). National Survey Results on Drug Use from The Monitoring the Future Study, 1975-1999. Public Health Service. National Institutes of Health. 2000.

Wechsler, H; Davenport A; Dowdall G; Moeykens B \& Castillo S. 1994. Health and Behavioral consequences of binge drinking in college: a national survey of students at 140 campuses.

Journal of the American Medical Association 272: 1672-1677.

Wechsler H., Dowdall G; Maenner G.; Gledhill-Hoyt J; and Lee H. 1998. Changes in binge rinking and related problems among American College students between 1993 and 1997. Journal of American College Health 47: 57-68.

Wechsler, H., Kelley K; Weitzman ER; San Giovanni JP; Seibring M. 2000a. What Colleges are Doing About Student Binge Drinking: A survey of College Administrators. Journal of American College Health 48 (March 2000): 219-226.

Wechsler H., Lee JE; Kuo M; Lee H. 2000b. College Binge Drinking in the 1990s: A Continuing Problem. Journal of American College Health 48 (March 2000): 199-210.

Wechsler H., Lee JE; Nelson TF; Lee H. 2001. Drinking Levels, Alcohol Problems and Secondhand Effects in Substance-Free College Residences: Results of a national study. Journal of Studies on Alcohol 62(1): 23-31.

Wechsler, H., Lee, JE., Gledhill-Hoyt, J, Nelson, TF. 2001. Alcohol Use and Problems at Colleges Banning Alcohol: Results of a National Survey. Journal of Studies on Alcohol, 62(2): 133-141 
Table 1

Summary Statistics

\begin{tabular}{|c|c|c|c|c|}
\hline \begin{tabular}{|c|} 
Variable \\
\end{tabular} & Mean & Std Dev & Min & Max \\
\hline $\mathrm{CPI}$ deflated price of an oz of commercial grade $\mathrm{MJ}^{\mathrm{a}}$ & 0.667 & 0.191 & 0.267 & 1.081 \\
\hline miles from school to DEA 19 cities reporting office match & 35.707 & 43.175 & 0.3 & 289.7 \\
\hline out of state match between school and DEA reporting office & 0.046 & 0.210 & 0 & 1 \\
\hline $\mathrm{CPI}$ deflated max fine for possession of one oz of $\mathrm{MJ}^{\mathrm{a}}$ & 39.854 & 298.934 & 0 & 3460.208 \\
\hline Indicator for marijuana use decriminalized & 0.288 & 0.453 & 0 & 1 \\
\hline alcohol consumption banned on campus & 0.192 & 0.394 & 0 & 1 \\
\hline alcohol free dorms are available on campus & 0.492 & 0.500 & 0 & 1 \\
\hline CPI deflated price of cigarettes ${ }^{a}$ & 1.397 & 0.310 & 0.919 & 2.154 \\
\hline CPI deflated (state and federal) beer tax ${ }^{a}$ & 0.011 & 0.003 & 0.009 & 0.025 \\
\hline one off campus bar within a mile of campus & 0.027 & 0.162 & 0 & 1 \\
\hline greater than one off campus bar within a mile of campus & 0.891 & 0.311 & 0 & 1 \\
\hline Indicator for state level restrictions on happy hours & 0.463 & 0.499 & 0 & 1 \\
\hline Indicator for state level restrictions on low prices & 0.420 & 0.494 & 0 & 1 \\
\hline Indicator for state level open container laws & 0.520 & 0.500 & 0 & 1 \\
\hline Male & 0.407 & 0.491 & 0 & 1 \\
\hline Age & 21.010 & 2.244 & 15 & 26 \\
\hline Age squared & 446.443 & 97.722 & 225 & 676 \\
\hline Hispanic & 0.064 & 0.244 & 0 & 1 \\
\hline African American & 0.052 & 0.222 & 0 & 1 \\
\hline Asian & 0.071 & 0.257 & 0 & 1 \\
\hline Native American & 0.006 & 0.076 & 0 & 1 \\
\hline Other Race & 0.066 & 0.248 & 0 & 1 \\
\hline Raised Catholic & 0.366 & 0.482 & 0 & 1 \\
\hline Raised Jewish & 0.035 & 0.183 & 0 & 1 \\
\hline Raised Moslem & 0.008 & 0.091 & 0 & 1 \\
\hline Raised Protestant & 0.368 & 0.482 & 0 & 1 \\
\hline Raised other religion & 0.099 & 0.299 & 0 & 1 \\
\hline At least one parent completed college & 0.809 & 0.393 & 0 & 1 \\
\hline No father present & 0.026 & 0.160 & 0 & 1 \\
\hline Father former drinker & 0.022 & 0.146 & 0 & 1 \\
\hline Father infrequent drinker & 0.421 & 0.494 & 0 & 1 \\
\hline Father moderate drinker & 0.210 & 0.407 & 0 & 1 \\
\hline Father heavy drinker & 0.055 & 0.228 & 0 & 1 \\
\hline Father problem drinker & 0.059 & 0.235 & 0 & 1 \\
\hline No mother present & 0.008 & 0.091 & 0 & 1 \\
\hline Mother former drinker & 0.007 & 0.083 & 0 & 1 \\
\hline Mother infrequent drinker & 0.505 & 0.500 & 0 & 1 \\
\hline Mother moderate drinker & 0.092 & 0.289 & 0 & 1 \\
\hline Mother heavy drinker & 0.012 & 0.108 & 0 & 1 \\
\hline Mother problem drinker & 0.013 & 0.115 & 0 & 1 \\
\hline Women's college & 0.043 & 0.202 & 0 & 1 \\
\hline African American College & 0.012 & 0.108 & 0 & 1 \\
\hline Commuter college & 0.145 & 0.352 & 0 & 1 \\
\hline Small private college & 0.115 & 0.319 & 0 & 1 \\
\hline Large private college & 0.161 & 0.367 & 0 & 1 \\
\hline Small public college & 0.141 & 0.348 & 0 & 1 \\
\hline Year $=1993$ & 0.361 & 0.480 & 0 & 1 \\
\hline Year=1997 & 0.340 & 0.474 & 0 & 1 \\
\hline
\end{tabular}

${ }^{a} \mathrm{CPI}=100$ in 1982-84 
Table 2.1

Alcohol and Marijuana Use in the Past Month

\begin{tabular}{|c|c|c|c|c|}
\hline & & & ijuana & \\
\hline & & NO & YES & Total \\
\hline & NO & 0.308 & 0.007 & 0.315 \\
\hline $\begin{array}{l}\text { Alcohol } \\
\text { Use }\end{array}$ & YES & 0.543 & 0.142 & 0.685 \\
\hline & Total & 0.851 & 0.149 & 1.000 \\
\hline
\end{tabular}

Table 2.2

Alcohol and Marijuana Use in the Past Year

\begin{tabular}{|c|c|c|c|c|}
\hline & & & ijuana & \\
\hline & & NO & YES & Total \\
\hline & NO & 0.173 & 0.003 & 0.177 \\
\hline $\begin{array}{l}\text { Alcohol } \\
\text { Use }\end{array}$ & YES & 0.560 & 0.263 & 0.823 \\
\hline & Total & 0.733 & 0.267 & 1.000 \\
\hline
\end{tabular}


Table 3

Thirty Day Prevalence of Marijuana and Alcohol Use

\begin{tabular}{|c|c|c|c|c|}
\hline & \multicolumn{2}{|c|}{ MARIJUANA } & \multicolumn{2}{|c|}{ ALCOHOL } \\
\hline & $\mathrm{dF} / \mathrm{dx}$ & Std. Err. & $\mathrm{dF} / \mathrm{dx}$ & Std. Err. \\
\hline \multicolumn{5}{|l|}{ State Indicators Included } \\
\hline CPI deflated price of an oz of commercial grade MJ & $-0.0612^{\star * *}$ & 0.0340 & $-0.0985^{\star *}$ & 0.0462 \\
\hline miles from school to DEA 19 cities reporting office match & $-0.0003^{* *}$ & 0.0001 & -0.0001 & 0.0003 \\
\hline out of state match between school and DEA reporting office & 0.0213 & 0.0417 & -0.0355 & 0.0568 \\
\hline $\mathrm{CPI}$ deflated max fine for possession of one oz of MJ & 1.64E-05 & 9.47E-06 & $-5.28 E-06$ & 7.85E-06 \\
\hline alcohol consumption banned on campus & $-0.0191^{* *}$ & 0.0083 & $-0.0361^{* * *}$ & 0.0192 \\
\hline one off campus bar within a mile of campus & 0.0055 & 0.0191 & 0.0236 & 0.0371 \\
\hline greater than one off campus bar within a mile of campus & -0.0102 & 0.0173 & $0.0386^{* * *}$ & 0.0216 \\
\hline alcohol free dorms are available on campus & 0.0047 & 0.0055 & 0.0032 & 0.0087 \\
\hline CPI deflated price of cigarettes & -0.0271 & 0.0345 & -0.0437 & 0.0480 \\
\hline Psuedo R2 & 0.0643 & & 0.1291 & \\
\hline \multicolumn{5}{|l|}{ No State Indicators Included } \\
\hline CPI deflated price of an oz of commercial grade MJ & -0.0049 & 0.0240 & -0.0427 & 0.0411 \\
\hline miles from school to DEA 19 cities reporting office match & $-0.0003^{* *}$ & 0.0001 & 0.0000 & 0.0002 \\
\hline out of state match between school and DEA reporting office & $0.0428^{* *}$ & 0.0267 & -0.0242 & 0.0457 \\
\hline decriminalization & 0.0089 & 0.0106 & 0.0056 & 0.0214 \\
\hline $\mathrm{CPI}$ deflated max fine for possession of one oz of $\mathrm{MJ}$ & $2.75 \mathrm{E}-05^{*}$ & 7.62E-06 & $-4.21 \mathrm{E}-06$ & 1.78E-05 \\
\hline CPI deflated beer tax & -2.8007 & 2.3563 & $-5.9409^{* * *}$ & 3.3298 \\
\hline state level restrictions on happy hours & $-0.0211^{* *}$ & 0.0101 & $-0.0261^{* *}$ & 0.0157 \\
\hline state level restrictions on low prices & 0.0047 & 0.0114 & 0.0222 & 0.0200 \\
\hline state level open container laws & -0.0121 & 0.0091 & $-0.0313^{* * *}$ & 0.0163 \\
\hline alcohol consumption banned on campus & $-0.0400^{*}$ & 0.0091 & $-0.0915^{\star}$ & 0.0311 \\
\hline one off campus bar within a mile of campus & 0.0145 & 0.0228 & 0.0677 & 0.0532 \\
\hline greater than one off campus bar within a mile of campus & -0.0071 & 0.0185 & $0.0965^{* *}$ & 0.0436 \\
\hline alcohol free dorms are available on campus & 0.0045 & 0.0061 & 0.0014 & 0.0105 \\
\hline $\mathrm{CPI}$ deflated price of cigarettes & 0.0186 & 0.0286 & -0.0346 & 0.0450 \\
\hline Psuedo R2 & 0.055 & & 0.1124 & \\
\hline
\end{tabular}

Standard errors are adjusted for clustering at the school level

$* * *$ denotes p-value $<0.10 ; * *$ denotes p-value $<0.05, *$ denotes $\mathrm{p}$-value $<0.01$. 
Table 4

Annual Prevalence of Marijuana and Alcohol Use

\begin{tabular}{|c|c|c|c|c|}
\hline & \multicolumn{2}{|c|}{ MARIJUANA } & \multicolumn{2}{|c|}{ ALCOHOL } \\
\hline & $\mathrm{dF} / \mathrm{dx}$ & Std. Err. & $\mathrm{dF} / \mathrm{dx}$ & Std. Err. \\
\hline \multicolumn{5}{|l|}{ State Indicators Included } \\
\hline CPI deflated price of an oz of commercial grade MJ & $-0.0863^{* * *}$ & 0.0456 & $-0.0621^{* * *}$ & 0.0320 \\
\hline miles from school to DEA 19 cities reporting office match & $-0.0005^{\star}$ & 0.0002 & -0.0002 & 0.0002 \\
\hline out of state match between school and DEA reporting office & 0.0255 & 0.0562 & -0.0125 & 0.0311 \\
\hline $\mathrm{CPI}$ deflated max fine for possession of one oz of MJ & 2.61E-05 & 1.66E-05 & $6.14 \mathrm{E}-06$ & 1.04E-05 \\
\hline alcohol consumption banned on campus & -0.0221 & 0.0135 & -0.0217 & 0.0141 \\
\hline one off campus bar within a mile of campus & 0.0017 & 0.0314 & -0.0012 & 0.0244 \\
\hline greater than one off campus bar within a mile of campus & -0.0031 & 0.0251 & 0.0173 & 0.0154 \\
\hline alcohol free dorms are available on campus & 0.0098 & 0.0080 & -0.0025 & 0.0061 \\
\hline $\begin{array}{l}\text { CPI deflated price of cigarettes } \\
\text { Psuedo R2 }\end{array}$ & $\begin{array}{r}-0.0267 \\
0.0698\end{array}$ & 0.0456 & $\begin{array}{r}-0.0466 \\
0.1652\end{array}$ & 0.0351 \\
\hline \multicolumn{5}{|l|}{ No State Indicators Included } \\
\hline $\mathrm{CPI}$ deflated price of an oz of commercial grade MJ & -0.0150 & 0.0355 & -0.0394 & 0.0319 \\
\hline miles from school to DEA 19 cities reporting office match & $-0.0005^{\star *}$ & 0.0002 & -0.0001 & 0.0002 \\
\hline out of state match between school and DEA reporting office & $0.0669^{* *}$ & 0.0342 & -0.0032 & 0.0320 \\
\hline decriminalization & 0.0105 & 0.0156 & 0.0166 & 0.0180 \\
\hline CPI deflated max fine for possession of one oz of MJ & 4.34E-05* & $1.20 \mathrm{E}-05$ & 2.74E-06 & 1.15E-05 \\
\hline CPI deflated beer tax & -5.0089 & 3.4831 & $-5.9409^{* * *}$ & 3.3298 \\
\hline state level restrictions on happy hours & $-0.0285^{\star *}$ & 0.0140 & $-0.0227^{* *}$ & 0.0116 \\
\hline state level restrictions on low prices & 0.0122 & 0.0161 & $0.0266^{* * *}$ & 0.0151 \\
\hline state level open container laws & -0.0138 & 0.0132 & $-0.0278^{* *}$ & 0.0132 \\
\hline alcohol consumption banned on campus & $-0.0578^{*}$ & 0.0149 & $-0.0698^{*}$ & 0.0286 \\
\hline one off campus bar within a mile of campus & 0.0182 & 0.0387 & 0.0438 & 0.0353 \\
\hline greater than one off campus bar within a mile of campus & -0.0056 & 0.0292 & $0.0716^{* *}$ & 0.0393 \\
\hline alcohol free dorms are available on campus & 0.0109 & 0.0090 & -0.0033 & 0.0081 \\
\hline CPI deflated price of cigarettes & 0.0502 & 0.0402 & $-0.0569^{* * *}$ & 0.0355 \\
\hline Psuedo R2 & 0.0591 & & 0.1395 & \\
\hline
\end{tabular}

Standard errors are adjusted for clustering at the school level

$* * *$ denotes p-value $<0.10$; ** denotes $\mathrm{p}$-value $<0.05, *$ denotes $\mathrm{p}$-value $<0.01$. 
Table 5

Thirty Day Prevalence of Marijuana and Alcohol Use

\begin{tabular}{|c|c|c|c|c|}
\hline & Males & Females & $\begin{array}{c}\text { Less Than } \\
21\end{array}$ & At least 21 \\
\hline \multicolumn{5}{|l|}{ MARIJUANA } \\
\hline $\mathrm{CPI}$ deflated price of an oz of commercial grade $\mathrm{MJ}$ & $\begin{array}{c}-0.0565^{* * *} \\
(0.0350)\end{array}$ & $\begin{array}{c}-0.0689^{* * *} \\
(0.0355)\end{array}$ & $\begin{array}{c}-0.0528 \\
(0.0340)\end{array}$ & $\begin{array}{c}-0.0673^{* * *} \\
(0.0362)\end{array}$ \\
\hline $\mathrm{CPI}$ deflated max fine for possession of one oz of MJ & $\begin{array}{c}1.07 \mathrm{E}-05 \\
(0.000008)\end{array}$ & $\begin{array}{c}2.43 \mathrm{E}-05^{* * *} \\
(0.000014)\end{array}$ & $\begin{array}{l}1.73 \mathrm{E}-05^{* * *} \\
(0.000008)\end{array}$ & $\begin{array}{c}1.50 \mathrm{E}-05 \\
(0.000011)\end{array}$ \\
\hline miles from school to DEA 19 cities reporting office match & {$\left[\begin{array}{c}-0.0003^{* *} \\
(0.0001)\end{array}\right.$} & $\begin{array}{c}-0.0003^{* *} \\
(0.0001)\end{array}$ & $\begin{array}{c}-0.0003^{* *} \\
(0.0001)\end{array}$ & $\begin{array}{c}-0.0003^{* *} \\
(0.0001)\end{array}$ \\
\hline out of state match between school and DEA reporting office & $\begin{array}{c}0.0235 \\
(0.0443)\end{array}$ & $\begin{array}{c}0.0189 \\
(0.0384)\end{array}$ & $\begin{array}{c}0.0152 \\
(0.0429)\end{array}$ & $\begin{array}{c}0.0269 \\
(0.0392)\end{array}$ \\
\hline alcohol consumption banned on campus & $\begin{array}{c}-0.0062 \\
(0.0073)\end{array}$ & $\begin{array}{l}-0.0275^{*} \\
(0.0100)\end{array}$ & $\begin{array}{c}-0.0206^{* *} \\
(0.0101)\end{array}$ & $\begin{array}{c}-0.0179^{* * *} \\
(0.0100)\end{array}$ \\
\hline alcohol free dorms are available on campus & $\begin{array}{c}0.0087 \\
(0.0084)\end{array}$ & $\begin{array}{c}0.0021 \\
(0.0063)\end{array}$ & $\begin{array}{c}0.0004 \\
(0.0069)\end{array}$ & $\begin{array}{c}0.0077 \\
(0.0065)\end{array}$ \\
\hline one off campus bar within a mile of campus & $\begin{array}{l}-0.0137 \\
(0.0196)\end{array}$ & $\begin{array}{c}0.0191 \\
(0.0237)\end{array}$ & $\begin{array}{l}-0.0012 \\
(0.0224)\end{array}$ & $\begin{array}{c}0.0135 \\
(0.0226)\end{array}$ \\
\hline more than one off campus bar within a mile of campus & $\begin{array}{l}-0.0223 \\
(0.0194)\end{array}$ & $\begin{array}{l}-0.0024 \\
(0.0179)\end{array}$ & $\begin{array}{l}-0.0099 \\
(0.0142)\end{array}$ & $\begin{array}{l}-0.0117 \\
(0.0229)\end{array}$ \\
\hline CPI deflated price of cigarettes & $\begin{array}{l}-0.0172 \\
(0.0351) \\
\end{array}$ & $\begin{array}{l}-0.0345 \\
(0.0349) \\
\end{array}$ & $\begin{array}{l}-0.0166 \\
(0.0349) \\
\end{array}$ & $\begin{array}{l}-0.0358 \\
(0.0357)\end{array}$ \\
\hline \multicolumn{5}{|l|}{$A L C O H O L$} \\
\hline $\mathrm{CPI}$ deflated price of an oz of commercial grade $\mathrm{MJ}$ & $\begin{array}{c}-0.1084^{* * *} \\
(0.0500)\end{array}$ & $\begin{array}{c}-0.0950^{* *} \\
(0.0458)\end{array}$ & $\begin{array}{c}-0.1039^{\star *} \\
(0.0490)\end{array}$ & $\begin{array}{c}-0.0923^{* * *} \\
(0.0483)\end{array}$ \\
\hline CPI deflated max fine for possession of one oz of MJ & $\begin{array}{c}-1.58 \mathrm{E}-05 \\
(0.000017)\end{array}$ & $\begin{array}{c}7.25 \mathrm{E}-06 \\
(0.000009)\end{array}$ & $\begin{array}{c}8.32 \mathrm{E}-06 \\
(0.000009)\end{array}$ & $\begin{array}{c}-1.76 \mathrm{E}-05 \\
(0.000019)\end{array}$ \\
\hline miles from school to DEA 19 cities reporting office match & $\begin{array}{c}-0.0001 \\
(0.0003)\end{array}$ & $\begin{array}{c}-4.45 \mathrm{E}-05 \\
(0.0003)\end{array}$ & $\begin{array}{c}0.0001 \\
(0.0003)\end{array}$ & $\begin{array}{l}-0.0003 \\
(0.0003)\end{array}$ \\
\hline out of state match between school and DEA reporting office & $\begin{array}{l}-0.0133 \\
(0.0597)\end{array}$ & $\begin{array}{l}-0.0536 \\
(0.0642)\end{array}$ & $\begin{array}{l}-0.0516 \\
(0.0595)\end{array}$ & $\begin{array}{l}-0.0173 \\
(0.0656)\end{array}$ \\
\hline alcohol consumption banned on campus & $\begin{array}{c}-0.0170 \\
(0.0218)\end{array}$ & $\begin{array}{l}-0.0504^{* *} \\
(0.0211)\end{array}$ & $\begin{array}{c}-0.0299 \\
(0.0225)\end{array}$ & $\begin{array}{l}-0.0402^{*} \\
(0.0181)\end{array}$ \\
\hline alcohol free dorms are available on campus & $\begin{array}{c}0.0025 \\
(0.0101)\end{array}$ & $\begin{array}{c}0.0032 \\
(0.0101)\end{array}$ & $\begin{array}{l}-0.0010 \\
(0.0103)\end{array}$ & $\begin{array}{c}0.0078 \\
(0.0099)\end{array}$ \\
\hline one off campus bar within a mile of campus & $\begin{array}{c}0.0297 \\
(0.0443)\end{array}$ & $\begin{array}{c}0.0217 \\
(0.0389)\end{array}$ & $\begin{array}{c}0.0242 \\
(0.0445)\end{array}$ & $\begin{array}{c}0.0199 \\
(0.0415)\end{array}$ \\
\hline more than one off campus bar within a mile of campus & $\begin{array}{c}0.0332 \\
(0.0216)\end{array}$ & $\begin{array}{c}0.0418^{* * *} \\
(0.0250)\end{array}$ & $\begin{array}{c}0.0372 \\
(0.0259)\end{array}$ & $\begin{array}{c}0.0379^{* * *} \\
(0.0228)\end{array}$ \\
\hline CPI deflated price of cigarettes & $\begin{array}{l}-0.0616 \\
(0.0498)\end{array}$ & $\begin{array}{l}-0.0380 \\
(0.0472)\end{array}$ & $\begin{array}{l}-0.0260 \\
(0.0484)\end{array}$ & $\begin{array}{l}-0.0472 \\
(0.0490)\end{array}$ \\
\hline
\end{tabular}

Standard errors are adjusted for clustering at the school level

$* * *$ denotes $\mathrm{p}$-value $<0.10 ; * *$ denotes $\mathrm{p}$-value $<0.05, *$ denotes $\mathrm{p}$-value $<0.01$. 
Table A.1

Thirty Day Prevalence of Alcohol Use

\begin{tabular}{|c|c|c|c|c|c|c|}
\hline & Without & State & Effects & With & State & Effects \\
\hline & $\mathrm{dF} / \mathrm{dx}$ & Std. Err. & z-score & $\mathrm{dF} / \mathrm{dx}$ & Std. Err. & z-score \\
\hline Price of MJ & -0.043 & 0.041 & -1.04 & -0.098 & 0.046 & -2.13 \\
\hline Miles from DEA site & 0.000 & 0.000 & -0.18 & 0.000 & 0.000 & -0.21 \\
\hline Out of state match & -0.024 & 0.046 & -0.54 & -0.035 & 0.057 & -0.64 \\
\hline Maximum real fine & $-4.21 \mathrm{E}-06$ & 0.0000178 & -0.24 & $-5.28 E-06$ & 7.85E-06 & -0.67 \\
\hline Decriminalized state & 0.006 & 0.021 & 0.26 & & & \\
\hline College ban on alcohol & -0.092 & 0.031 & -3.09 & -0.036 & 0.019 & -1.91 \\
\hline Alcohol free dorms & 0.001 & 0.010 & 0.13 & 0.003 & 0.009 & 0.37 \\
\hline One bar within mile of campus & 0.068 & 0.053 & 1.19 & 0.024 & 0.037 & 0.62 \\
\hline$>1$ bar within mile of campus & 0.096 & 0.044 & 2.33 & 0.039 & 0.022 & 1.82 \\
\hline Real beer tax & -6.835 & 4.187 & -1.65 & & & \\
\hline State restricts happy hour sales & -0.026 & 0.016 & -1.66 & & & \\
\hline State restricts pitcher sales & 0.022 & 0.020 & 1.11 & & & \\
\hline State restricts open containers & -0.031 & 0.016 & -1.93 & & & \\
\hline Real price of cigarettes & -0.035 & 0.045 & -0.77 & -0.044 & 0.048 & -0.91 \\
\hline Male & 0.045 & 0.006 & 7.75 & 0.045 & 0.006 & 7.77 \\
\hline Age & 0.486 & 0.024 & 21 & 0.485 & 0.023 & 21.16 \\
\hline Age squared & -0.011 & 0.001 & -20.39 & -0.011 & 0.001 & -20.38 \\
\hline Hispanic & -0.023 & 0.012 & -1.93 & -0.015 & 0.012 & -1.29 \\
\hline African American & -0.208 & 0.018 & -12.14 & -0.216 & 0.016 & -14.46 \\
\hline Asian & -0.215 & 0.021 & -10.85 & -0.223 & 0.014 & -16.26 \\
\hline Native American & -0.008 & 0.036 & -0.24 & -0.010 & 0.036 & -0.29 \\
\hline Other Race & -0.075 & 0.014 & -5.38 & -0.074 & 0.013 & -5.71 \\
\hline Raised Catholic & 0.041 & 0.009 & 4.55 & 0.034 & 0.008 & 4.04 \\
\hline Raised Jewish & 0.042 & 0.017 & 2.35 & 0.028 & 0.016 & 1.7 \\
\hline Raised Moslem & -0.222 & 0.032 & -7.09 & -0.237 & 0.032 & -7.57 \\
\hline Raised Protestant & -0.056 & 0.009 & -6.41 & -0.053 & 0.008 & -6.37 \\
\hline Raised other religion & -0.058 & 0.018 & -3.36 & -0.039 & 0.011 & -3.65 \\
\hline One parent completed college & 0.052 & 0.008 & 6.64 & 0.056 & 0.007 & 7.71 \\
\hline No father present & 0.082 & 0.015 & 5.29 & 0.073 & 0.014 & 4.97 \\
\hline Father former drinker & 0.095 & 0.016 & 5.41 & 0.083 & 0.015 & 5.04 \\
\hline Father infrequent drinker & 0.121 & 0.012 & 10.43 & 0.106 & 0.007 & 14.92 \\
\hline Father moderate drinker & 0.137 & 0.011 & 12.16 & 0.125 & 0.007 & 15.98 \\
\hline Father heavy drinker & 0.119 & 0.013 & 8.73 & 0.109 & 0.010 & 9.34 \\
\hline Father problem drinker & 0.094 & 0.014 & 6.38 & 0.080 & 0.012 & 6.39 \\
\hline No mother present & -0.084 & 0.029 & -3.03 & -0.084 & 0.029 & -2.99 \\
\hline Mother former drinker & 0.073 & 0.025 & 2.78 & 0.067 & 0.026 & 2.42 \\
\hline Mother infrequent drinker & 0.086 & 0.008 & 11.95 & 0.078 & 0.006 & 12.26 \\
\hline Mother moderate drinker & 0.125 & 0.011 & 11.25 & 0.117 & 0.010 & 11.13 \\
\hline Mother heavy drinker & 0.090 & 0.020 & 4.05 & 0.085 & 0.021 & 3.78 \\
\hline Mother problem drinker & 0.021 & 0.021 & 0.96 & 0.014 & 0.021 & 0.65 \\
\hline Womens college & -0.077 & 0.030 & -2.66 & -0.080 & 0.031 & -2.72 \\
\hline African American College & -0.014 & 0.045 & -0.32 & -0.037 & 0.034 & -1.09 \\
\hline Commuter college & -0.091 & 0.017 & -5.46 & -0.085 & 0.022 & -4.02 \\
\hline Small private college & -0.038 & 0.029 & -1.34 & -0.072 & 0.026 & -2.83 \\
\hline Large private college & -0.039 & 0.043 & -0.94 & -0.007 & 0.020 & -0.36 \\
\hline Small public college & -0.024 & 0.028 & -0.85 & -0.057 & 0.020 & -2.84 \\
\hline Year $=1993$ & 0.018 & 0.028 & 0.63 & 0.018 & 0.030 & 0.59 \\
\hline Year $=1997$ & -0.028 & 0.027 & -1.02 & -0.027 & 0.028 & -0.99 \\
\hline log likelihood & -20487.39 & & & -20102.294 & & \\
\hline
\end{tabular}


Psuedo R2

0.1124

37065

0.1291 37065

$N=$ 
Table A.2

Thirty Day Prevalence of Marijuana Use

\begin{tabular}{|c|c|c|c|c|c|c|}
\hline & Without & State & Effects & With & State $\mathbf{s}$ & Effect \\
\hline & $\mathrm{dF} / \mathrm{dx}$ & Std. Err. & z-score & dF/dx & Std. Err. & z-score \\
\hline Price of MJ & -0.005 & 0.024 & -0.2 & -0.061 & 0.034 & -1.81 \\
\hline Miles from DEA site & 0.000 & 0.000 & -2.47 & 0.000 & 0.000 & -2.37 \\
\hline Out of state match & 0.043 & 0.027 & 1.73 & 0.021 & 0.042 & 0.53 \\
\hline Maximum real fine & 0.000 & 0.000 & 3.61 & 0.000 & 0.000 & 1.74 \\
\hline Decriminalized state & 0.009 & 0.011 & 0.85 & & & \\
\hline College ban on alcohol & -0.040 & 0.009 & -4.05 & -0.019 & 0.008 & -2.21 \\
\hline Alcohol free dorms & 0.004 & 0.006 & 0.74 & 0.005 & 0.006 & 0.86 \\
\hline One bar within mile of campus & 0.014 & 0.023 & 0.65 & 0.006 & 0.019 & 0.29 \\
\hline$>1$ bar within mile of campus & -0.007 & 0.018 & -0.39 & -0.010 & 0.017 & -0.6 \\
\hline Real beer tax & -2.801 & 2.356 & -1.18 & & & \\
\hline State restricts happy hour sales & -0.021 & 0.010 & -2.08 & & & \\
\hline State restricts pitcher sales & 0.005 & 0.011 & 0.41 & & & \\
\hline State restricts open containers & -0.012 & 0.009 & -1.34 & & & \\
\hline Real price of cigarettes & 0.019 & 0.029 & 0.65 & -0.027 & 0.035 & -0.78 \\
\hline Male & 0.044 & 0.004 & 11.34 & 0.043 & 0.004 & 11.41 \\
\hline Age & 0.030 & 0.014 & 2.04 & 0.026 & 0.014 & 1.83 \\
\hline Age squared & -0.001 & 0.000 & -2.65 & -0.001 & 0.000 & -2.39 \\
\hline Hispanic & -0.023 & 0.009 & -2.31 & -0.018 & 0.009 & -1.85 \\
\hline African American & -0.044 & 0.009 & -4.5 & -0.043 & 0.008 & -4.42 \\
\hline Asian & -0.074 & 0.006 & -9.74 & -0.073 & 0.005 & -10.9 \\
\hline Native American & 0.096 & 0.035 & 3.2 & 0.097 & 0.034 & 3.36 \\
\hline Other Race & 0.012 & 0.010 & 1.2 & 0.011 & 0.010 & 1.12 \\
\hline Raised Catholic & -0.024 & 0.007 & -3.69 & -0.024 & 0.006 & -4.1 \\
\hline Raised Jewish & 0.062 & 0.012 & 5.71 & 0.053 & 0.012 & 4.76 \\
\hline Raised Moslem & -0.045 & 0.022 & -1.77 & -0.047 & 0.021 & -1.88 \\
\hline Raised Protestant & -0.051 & 0.006 & -8.18 & -0.047 & 0.006 & -8.13 \\
\hline Raised other religion & -0.038 & 0.008 & -4.53 & -0.031 & 0.007 & -3.99 \\
\hline One parent completed college & 0.040 & 0.005 & 8.19 & 0.038 & 0.004 & 8.33 \\
\hline No father present & 0.059 & 0.015 & 4.32 & 0.053 & 0.015 & 4.02 \\
\hline Father former drinker & 0.093 & 0.016 & 6.85 & 0.084 & 0.015 & 6.57 \\
\hline Father infrequent drinker & 0.026 & 0.006 & 4.11 & 0.021 & 0.005 & 3.88 \\
\hline Father moderate drinker & 0.047 & 0.008 & 6.29 & 0.041 & 0.007 & 6.15 \\
\hline Father heavy drinker & 0.071 & 0.012 & 6.54 & 0.066 & 0.011 & 6.51 \\
\hline Father problem drinker & 0.063 & 0.012 & 5.91 & 0.056 & 0.011 & 5.65 \\
\hline No mother present & -0.025 & 0.020 & -1.13 & -0.024 & 0.020 & -1.08 \\
\hline Mother former drinker & 0.045 & 0.024 & 2.08 & 0.039 & 0.023 & 1.8 \\
\hline Mother infrequent drinker & 0.022 & 0.005 & 4.14 & 0.019 & 0.005 & 3.76 \\
\hline Mother moderate drinker & 0.072 & 0.010 & 7.71 & 0.065 & 0.010 & 7.38 \\
\hline Mother heavy drinker & 0.066 & 0.020 & 3.68 & 0.059 & 0.019 & 3.46 \\
\hline Mother problem drinker & 0.081 & 0.021 & 4.34 & 0.076 & 0.020 & 4.29 \\
\hline Womens college & -0.061 & 0.018 & -2.77 & -0.065 & 0.018 & -2.76 \\
\hline African American College & 0.027 & 0.026 & 1.11 & 0.005 & 0.037 & 0.14 \\
\hline Commuter college & -0.033 & 0.011 & -2.72 & -0.041 & 0.012 & -3.11 \\
\hline Small private college & -0.020 & 0.012 & -1.64 & -0.017 & 0.013 & -1.24 \\
\hline Large private college & -0.018 & 0.013 & -1.29 & -0.025 & 0.011 & -2.14 \\
\hline Small public college & -0.002 & 0.016 & -0.1 & -0.014 & 0.013 & -1.04 \\
\hline Year $=1993$ & -0.027 & 0.017 & -1.53 & -0.047 & 0.020 & -2.33 \\
\hline Year=1997 & 0.004 & 0.016 & 0.22 & -0.016 & 0.018 & -0.84 \\
\hline log likelihood & -14877.7 & & & -14732.326 & & \\
\hline
\end{tabular}


Psuedo R2

participation rate

$\mathrm{N}=$

0.055

37483

0.0643

37483 